\title{
Endoscopic Retrograde Cholangiopancreatography at Dhulikhel hospital: Outcome Analysis
}

\author{
Gurung RB, Purbey B, Koju R, Bedi TRS
}

Department of Internal Medicine

Dhulikhel Hospital- Kathmandu University Hospital Kathmandu University School of medical Science

Dhulikhel Hospital, Kavre, Nepal

\section{Corresponding Author}

Ram Bahadur Gurung

Department of Internal Medicine

Dhulikhel Hospital- Kathmandu University Hospital Kathmandu University School of medical Science

Dhulikhel, Kavre, Nepal

E-mail: rambgurung7@gmail.com

\section{Citation}

Gurung RB , Purbey B, Koju R, Bedi TRS. Endoscopic Retrograde Pancreato Cholangiography (ERCP) at Dhulikhel hospital: Outcome Analysis. Kathmandu Univ Med J 2014;45(1):55-59.

\section{ABSTRACT}

\section{Background}

Endoscopic Retrograde Cholangiopancreatography (ERCP) is an important but potentially invasive therapeutic procedure in treating various pancreatobiliary conditions. In Nepal, the ERCP services is limited to a few tertiary care centers mostly in the capital, Kathmandu. Dhulikhel hospital has started ERCP since 2011 providing services to patients from all over the country. The study analyzes the outcome from data since August 2011 to 2013 August.

\section{Objective}

To analyze the results of ERCP done in Dhulikhel hospital, Kathmandu University hospital.

\section{Method}

This is a retrospective study. The ERCP records of all the patients done since August 2011 to August 2013 were retrieved. A total of 516 attempts of ERCP were done since August 2011 to August 2013. Out of these, 423 were included for the analysis. The repeat ERCP for the same patient due to failed cannulation or patients undergone ERCP but incomplete documentation were excluded. The demographic data, indications, the findings, the outcome in terms of success or failure to cannulation, success or failure of stone extraction, stenting and complications were all derived and analyzed. SPSS 16 version was employed for data management and analysis.

\section{Result}

The female: male ratio was found to be $1.7: 1$. The mean age of patients were $50.57 \pm 17.8$ Years. The most common indication for ERCP were: choledocholithiasis 208(49.17\%); followed by: obstructive jaundice $69(16.3 \%$ ) of undetermined cause, acute biliary pancreatitis $26(6.4 \%)$, suspected bile duct injury during cholecystectomy $18(4.2 \%)$, periampullary growth $21(4.96 \%)$, Cholangiocarcinoma $12(2.8 \%)$, chronic pancreatitis 10 (2.3\%), CBD stent exchange 23(5.43\%), dilated cbd 21(4.96\%), acute cholangitis $14(3.3 \%)$.The most common finding was CBD stone in $308(72.81 \%)$, normal in $51(12.1 \%)$, bile duct stricture in $45(10.63 \%)$. Bile duct injury during cholecystectomy was found in $13(3.1 \%)$, biliary obstruction due to ampullary growth and pancreatic head mass was found in $21(4.96 \%)$ and $6(1.41 \%)$ respectively. Choledochal cyst was found in $5(1.2 \%)$, chronic pancreatitis in $7(1.7 \%)$. Biliary fascioliasis was found in one $(0.24 \%)$; and roundworm in $1(0.24)$.The most common complication was acute pancreatitis in $17(4 \%)$, post-ERCP cholangitis $6(1.4 \%)$, bleeding $6(1.4 \%)$, duodenal perforation in $1(0.2 \%)$, arrhythmia in $1(0.2 \%)$ and one death $(0.2 \%)$.

\section{Conclusion}

ERCP has been a potentially emerging therapeutic tool for various pancreato-biliary disorders in Nepal.

\section{KEY WORDS}

Cholidocholelithiasis, endoscopic retrograde cholangio Pancreatography, stenting 


\section{INTRODUCTION}

The ERCP was first introduced in $1968 .{ }^{1}$ It has now become a widely performed procedure worldwide and has become a well established diagnostic and therapeutic tool for a variety of pancreato-biliary diseases, such as-treatment of choledocholithiasis, the diagnosis and management of biliary and pancreatic tumors, and the management of biliary injuries after surgery. ${ }^{2-4}$ However, the evolution of the role of ERCP has occurred simultaneously with the emerging novel but sensitive diagnostic and therapeutic modalities, such as magnetic resonance imaging (MRCP), laparoscopic cholecystectomy and CBD exploration, and EUS. Because of this technological advancement, the role of ERCP has become largely therapeutic at present time. Moreover, the ERCP is invasive, technically demanding procedure, and carries a potentially serious morbidity and mortality.

In Nepal, pancreato-biliary disorders are commonly encountered in day to day clinical practice requiring ERCP in most occasions. The availability of newer diagnostic modalities such as MRCP and EUS are limited in Nepal. Likewise, the hospitals which provide ERCP services are also limited and mostly confined within the capital city in Nepal. Therefore, patients from outside Kathmandu are normally referred to centers in Kathmandu or likely to go to India at the border area. Moreover, the ERCP incurs an extra high economic burden to most of the Nepalese patients most of whom are from poor socioeconomic strata.

Dhulikhel hospital is a university hospital of Kathmandu University, located $30 \mathrm{~km}$ outside the Kathmandu valley, providing health care to largely the people from rural community. ERCP has been introduced since early 2011 and now has become one of the referral centers for ERCP in the country. This study was carried out in order to evaluate the outcome of the procedure done in the two year time period.

\section{METHOD}

This is a retrospective study. The ERCP documentation files of all the patients done since August 2011 to August 2013 were retrieved. The saved cholangiogram images of each patient who had undergone ERCP were also reviewed and analyzed. The total number of ERCP done in this period was 516; out of these, 423 cases were included and analyzed for the study. The repeated procedures or procedure with incomplete informations were excluded in the analysis. The demographic data and indications for ERCP were studied. The outcome of ERCP was analyzed in terms of:

- Success or failure to cannulation,

- Success or failure of stone extraction; partial stone extraction without complete duct clearance was counted as failed extraction

- Success of stenting of bile or pancreatic duct, and
- Complications during or immediately after the procedure.

The total findings at ERCP, both duodenoscopic and radiographic were also recorded and analyzed. SPSS 16 version was employed for data management and analysis.

\section{RESULT}

A total of 423 patients undergoing ERCP since August 2011 to August 2013 were analyzed. The female: male ratio was found to be $1.7: 1$. The mean age of patients were $50.57 \pm 17.8$ Years. (Table 1 ) The most common indication Table 1. Demographic characteristics.

\begin{tabular}{|c|c|}
\hline Variables & Frequency (Percentage) \\
\hline Age (mean) & $50.57 \pm 17.78$ \\
\hline \multicolumn{2}{|c|}{ Sex } \\
\hline Male & $154(36.4)$ \\
\hline Female & $269(63.6)$ \\
\hline \multicolumn{2}{|c|}{ Ethnicity } \\
\hline Brahmin/Chhetri & 152 (35.9) \\
\hline Newar & $99(23.4)$ \\
\hline Mongol & $106(25.1)$ \\
\hline Dalits & $266.1)$ \\
\hline Others & $40(9.5)$ \\
\hline
\end{tabular}

for ERCP (Table 2) were: choledocholithiasis in 208(49.2\%); followed by: obstructive jaundice of undetermined cause in $69(16.3 \%)$, acute biliary pancreatitis in 26 (6.4\%), suspected bile duct injury during cholecystectomy in 18(4.2\%), periampullary growth in $21(4.96 \%)$, Cholangiocarcinoma in $12(2.8 \%)$, chronic pancreatitis in $10(2.3 \%)$, CBD stent exchange in $23(5.43 \%)$, dilated cbd in $21(4.96 \%)$, acute cholangitis in 14(3.3\%); and CBD stricture in $1(0.23 \%)$.

Table 2. Indications for ERCP procedure.

\begin{tabular}{|lc|}
\multicolumn{1}{|c}{ Variables (Indications) } & $\begin{array}{c}\text { Frequency (Percent- } \\
\text { age) }\end{array}$ \\
\hline Cholidocholelithiasis & $208(49.2)$ \\
\hline Obstructive jaundice of undetermined cause & $69(16.3)$ \\
\hline Acute biliary pancreatitis & $26(6.4)$ \\
\hline $\begin{array}{l}\text { Suspected Bileduct injury during lap cholecys- } \\
\text { tectomy }\end{array}$ & $18(4.2)$ \\
\hline Periampullary growth & $21(4.9)$ \\
\hline Cholangio carcinoma & $12(2.8)$ \\
\hline Chronic pancreatitis & $10(2.3)$ \\
\hline CBD stent exchange & $23(5.4)$ \\
\hline Dilated CBD & $21(4.9)$ \\
\hline Acute Cholangitis & $14(3.3)$ \\
\hline CBD stricture & $1(0.2)$
\end{tabular}

Among the ERCP findings (Table 3), the most common finding was CBD stone in 209(49.40\%); out of which, 75 (35.9\%) were giant stones, 9(4.3\%) were impacted either at the ampulla or proximal duct; and in 15(7.17) patients stones were intra-hepatically located. In 51(12.1\%) 
patients, the findings were normal. Bile duct stricture was found in 45(10.63\%); out of which, 33(73.33\%) were believed to be malignant stricture and $12(26 \%)$ due to benign cause. Bile duct injury during cholecystectomy was found in $13(3.1 \%)$, biliary obstruction due to ampullary growth and pancreatic head mass was found in $21(4.96 \%)$ and $6(1.41 \%)$ respectively. Duodenum diverticulum was found in $18(4.3 \%)$ patients. Choledochal cyst was found in $5(1.2 \%)$, chronic pancreatitis in $7(1.7 \%)$, Mirrizi's syndrome in $4(0.9 \%)$, duodenobiliary fistula in $6(1.41 \%)$, biliary fascioliasis in one $(0.24 \%)$, roundworm in $1(0.24)$ and portal biliopathy in $1(0.24)$. Selective cannulation of desired duct Table 3. Findings of ERCP.

\begin{tabular}{|lc|}
\hline \multicolumn{1}{|c}{ Variables (Indications) } & $\begin{array}{c}\text { Frequency (Percent- } \\
\text { age) }\end{array}$ \\
\hline Cholidocholelithiasis & $209(49.4)$ \\
\hline Normal findings & $51(12.1)$ \\
\hline CBD stricture & $45(10.7)$ \\
\hline Ampullary growth & $21(5.0)$ \\
\hline DU diverticulum & $18(4.3)$ \\
\hline Post cholecystectomy bile duct injury & $13(3.1)$ \\
\hline Chronic pancreatitis & $7(1.7)$ \\
\hline Ca head of pancreasee & $6(1.4)$ \\
\hline Duedenobiliary fistula & $6(1.4)$ \\
\hline Choledocol cyst & $5(1.2)$ \\
\hline Mirrizi Syndrome & $4(0.9)$ \\
\hline Portal biliopathy & $1(0.2)$ \\
\hline Round worm & $1(0.2)$ \\
\hline Biliary fascioliasis & $1(0.2)$ \\
\hline
\end{tabular}

was achieved 94.1\%; $4 \%$ of patients were cannulated at second ERCP attempt. The complete CBD clearance was achieved in up to $81.5 \%$ of patients. CBD Stenting was done in $120(28.35 \%)$ patients with success rate up to $95.8 \%$. Of these, $54.2 \%$ stenting was for obstructing malignant stricture; $29.2 \%$ for obstructing stone with failed extraction, $10.0 \%$ benign stricture, and $6.7 \%$ for post cholecystectomy bile duct injury.

The most common complication was acute pancreatitis in $17(4 \%)$ patients; two $(0.5 \%)$ had severe pancreatitis requiring prolonged hospitalization. Post-ERCP cholangitis in $6(1.4 \%)$, bleeding in $6(1.4 \%)$, duodenal perforation in 1 $(0.2 \%)$, arrhythmia in $1(0.2 \%)$ and one death $(0.2 \%)$.

\section{DISCUSSION}

Pancreato-biliary diseases requiring ERCP is common in Nepal as shown by our study done in a period of two years. Our study showed the three most common indications (Table 2) for ERCP as: choledocholithiasis (49.17\%), obstructive jaundice (16.3\%) with no definitive cause and acute biliary pancreatitis (6.4\%). The indication for suspected biliary injury during cholecystectomy was $18(4.2 \%)$. Various population based studies have shown incidence of bile duct injuries as ranging from 0.1 to $0.5 .^{5-7}$ In a study done in one of the teaching hospitals in Nepal showed post- cholecystectomy bile duct injury up to $2.6 \%{ }^{8}$ The relatively high $(4.2 \%)$ rate of bile duct injuries in our study is due to the referral from the different hospitals in Nepal. Nevertheless, this figure underscores the fact that bile duct injury is an important and prevalent complication of cholecystectomy in Nepal.

The indication of ERCP (Table 2) for diagnostic purpose was $4.96 \%$ in this study. This finding probably reflects the limited use of MRCP, and unavailability of EUS in Nepal thus prompting low threshold for indicating ERCP. However, compared with the figure from a study done at Bir hospital where up to $48.3 \%$ out of 662 patients had diagnostic ERCP is much lower. ${ }^{9}$ With the availability and improvement in the non-invasive tools such as MRCP and EUS the number of diagnostic indications can be anticipated to decrease in the future.

The most common findings during ERCP (Table 3) were: CBD stone in $72.81 \%$, out of which, 75 (35.9\%) were large (Fig 1).The significant number of large bile duct stone also reflects a long standing nature of stone and the late detection. In $12.1 \%$ of patients the findings were normal. The normal finding was reported in up to $32.41 \%$ in the study done at Bir hospital. ${ }^{9}$ Bile duct stricture was found in $10.63 \%$; out of which $73.33 \%$ was believed to be malignant; although, histopathological confirmation of the diagnosis was not possible in all cases.

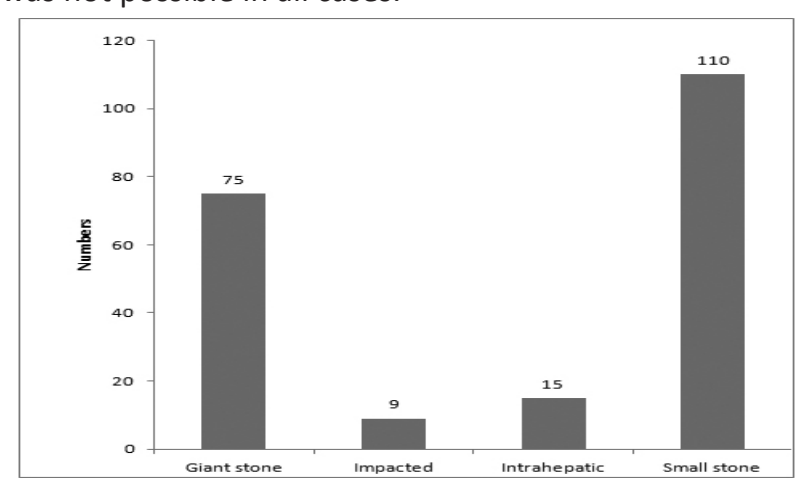

Figure 1. Types of stones found during ERCP procedures.

Biliary obstruction due to ampullary growth and pancreatic head mass was found in $4.96 \%$ and $1.41 \%$, respectively. Similar rates had been reported in the study from Bir hospital (5.24 and $2.8 \%$ respectively). ${ }^{9}$

Choledochal cyst was found in $1.2 \%$ of cases in our study. Although, reported to be rare with incidence of 1/100000150000 in western countries; this congenital defect has been reported more common in Asia with incidence rate up to $1 / 1000 .^{10}$ Out of 662 patients, Shrestha et al found choledochal cyst in up to 10 cases (1.64\%) in Bir hospital. ${ }^{9}$

In this study, biliary fascioliasis and roundworm were detected in $1(0.24 \%)$ patient respectively. Although, biliary ascariasis is commonly reported findings in most studies from developing world. ${ }^{11-14}$ Biliary fascioliasis is probably the first case found in our study from Nepal. This finding 
confirms that bilary fasciliosis exists in Nepal ; and, should prompt suspicion in cases with biliary obstruction.The selective duct cannulation was successful in $94.1 \%$. In $4 \%$ of cases the cannulation was successful at second ERCP attempt.

In our study, the complete stone extraction was achieved in $81.5 \%$. This comparatively lower rate of CBD clearance as Table 4. Indications for bile duct stenting .

$\mathrm{n}=\mathbf{1 2 0}$

\begin{tabular}{|lc|}
\hline Variables & Frequency (Percentage) \\
\hline Malignant stricture & $65(54.2)$ \\
\hline $\begin{array}{l}\text { Obstructing stone with failed } \\
\text { extraction }\end{array}$ & $35(29.2)$ \\
$\begin{array}{l}\text { Post cholecystectomy bile duct } \\
\text { injury }\end{array}$ & $8(6.7)$ \\
\hline Benign Stricture & $12(10.0)$
\end{tabular}

compared to most studies is attributable to higher incidence of large stones, stone impaction in the duct intra-hepatic location of stones and lack of mechanical lithotriptor in the initial period of starting ERCP at this institution. ${ }^{15-18}$

CBD stenting was done in 120 (28.4\%) patients. The most common indication (Table 4) for stenting was tumor obstruction (54.2\%) and failed stone extraction (8.2\%). The success rate for CBD stenting was $95.8 \%$. PD stenting was done only in $2(0.5 \%)$. Low rate of pancreatic duct stenting is due to lower number of indications for PD stenting compared to biliary tract diseases requiring stenting.

Among the complications after ERCP (Table 5), acute pancreatitis was found in up to $4 \%$ (17); in 2(0.5\%) developed severe pancreatitis requiring prolonged hospitalization. However, there was no death due to pancreatitis. The current rate of pancreatitis in clinical practice is variable. Reports suggest that in academic centers the rate of pancreatitis varies from between $1 \%$ to $30 \%$ of procedures. ${ }^{19,20}$ Our rate of acute pancreatitis is comparable to most of the literatures. This reasonably low incidence of PEP is attributable to the use of prophylactic PD stenting we have been practicing for high risk patients in our institute. In our study, 6(1.4\%) patients developed acute cholangitis which were mostly related with stenting in hilar growth. Acute cholangitis has been reported to be $0.4 \%-1.8 \%$ of ERCP patients in various studies. ${ }^{21-23}$

There was one $(0.2 \%)$ death in our study which was due to a severe sepsis and multiorgan failure following ERCP for failed stone extraction. The rate of mortality associated with ERCP has been reported at up to $1.0 \%$ with a mean of $0.4 \% .{ }^{21,22}$ The bleeding was found in $6(1.4 \%)$ cases and one $(0.2 \%)$ had severe bleeding post sphincterotomy requiring blood transfusion. Bleeding risk during ERCP is $0.3 \%-1.3 \%$, and this rate is even higher with sphincterotomy and in patients undergoing anticoagulant therapy. . $^{21,22,24,25}$ None of the patients in our study was on anticoagulant drugs. Duodenal perforation occurred in one $(0.2 \%)$ patient with infiltrating duodenal tumor. But no case of peforation related to sphincterotomy was found in our study.

Our study had some limitations. This is a retrospective study, some of the findings were missing in the documentations and not included in the study. Most of the patients were referred patients from another hospitals, and not reviewed subsequently. Lack of adequate number and quality of accessories in the initial period of starting ERCP is likely to affect the outcome of the procedure.

\section{CONCLUSION}

In conclusion, our study showed that biliary disorders requiring ERCP are common problem in Nepal. Whereas ERCP has a definite therapeutic role in treating these conditions but also carries a significant risk of morbidity and mortality. Appropriate indications to ERCP and judicious use of non-interventional technique such as MRCP and EUS will help minimize the complications.

\section{REFERENCES}

1. McCune WS, Shorb PE, Moscovitz H. Endoscopic cannulation of the ampulla of Vater: a preliminary report. Ann Surg. 1968;167:752-6.

2. Baron TH, Mallery JS, Hirota WK. The role of endoscopy in the evaluation and treatment of patients with pancreaticobiliary malignancy. Gastrointest Endosc. 2003;58:643-9.

3. Maple JT, Ben-Menachem T, Anderson MA. The role of endoscopy in the evaluation of suspected choledocholithiasis. Gastrointest Endosc. 2010;71:1-9.

4. Costamagna G, Shah SK, Tringali A. Current management of postoperative complications and benign biliary strictures. Gastrointest Endosc Clin N Am. 2003;13:635-48.

5. Fletcher DR, Hobbs MS, Tan P, Valinsky L, Hockey RL, Pikora TJ et al. Complications of cholecystectomy: risks of the laparoscopic approach and protective effects of operative cholangiography: a populationbased study. Ann Surg. 1999;229: 449-457.

6. Cohen MM, Young W, Theriault ME, Hernandez R. Has laparoscopic cholecystectomy changed patterns of practice and patient outcome in Ontario? CMAJ. 1996; 154: 491-500.

7. Russell JC, Walsh SJ, Mattie AS, Lynch JT. Bile duct injuries, 1989-1993. A statewide experience. Connecticut Laparoscopic Cholecystectomy Registry. Arch Surg. 1996;131: 382-388.

8. Koirala U, Subba K, Thakur A, Joshi MR, Thapa P, Singh DR et.al. Biliary complications after laparoscopic cholecystectomy. J Nepal Health Res Counc. 2011 Apr;9(1):38-43.

9. Shrestha, S. Shrestha, D. Shrestha. Endoscopic therapy cholangiopancreatic disease. Post-graduate Medical Journal, NAMS $2008 ; 8(1)$.

10. Singham J, Yoshida EM, Scudamore CH. Choledochal cysts: part 1 of 3: classification and pathogenesis. Can J Surg. 2009 Oct;52(5):434-40.

11. Cremin BJ, Fisher RM. Biliary ascariasis in childhood. AJR Am J Roentgenol. 1976;126:352-7.

12. Khuroo MS, Zargar SA. Biliary Ascriasis: A common cause of biliary and pancreatic disease in an endemic area. Gastroenterology. $1985 ; 88: 418-23$. 
13. Khuroo MS, Mahajan R, Zargar SA, Javid G, Sapru S. Prevalence of biliary tract disease in India: A sonographic study in adult population in India. Gut. 1989;30:201-5.

14. Yang SC, Laube PJ. Biliary ascariasis: Report of 19 cases. Ann Surg. 1946;123:299-303.

15. Quorain, AA, EM Ibrahim and AIA Sultan.1996. Diagnostic and therapeutic value of ERCP and prediction of outcome: A retrospective analysis. The Saudi J. of Gastroenterology. 2(3):138-141.

16. Demling L, K Senberth and JF Rilman. 1982 . A mechanical lithotripler. Endoscopy.14:100-101.

17. Zorgar, SA, B Khan, GN Yatloo, GM Gulzar. 2002. Endoscopic sphincterotomy in the management of the common bile duct stones: Results in 170 patients. JK Practitioner. 9(1):20-23.

18. Farrell RJ, Mahmud N, Noonan N, Kelleher D, Keeling PW. Diagnostic and therapeutic ERCP: a large single centre's experience. Ir J Med Sci 2001;170:176-180.

19. Freeman ML, Guda NM. Prevention of post-ERCP pancreatitis: a comprehensive review. Gastrointest Endosc. 2004;59:845-64.
20. Mallery JS, Baron TH, Dominitz JA. Standards of Practice Committee, American Society for Gastrointestinal Endoscopy: Complications of ERCP. Gastrointest Endosc. 2003;57:633-8.892.

21. Huang LY, Liu YX, Wu CR, Cui J, Zhang B. Application of endoscopic retrograde cholangiopancreatography in biliarypancreatic diseases. Chinese Med J. 2009; 122: 2967-72.

22. Penaloza-Ramirez A, Leal-Buitrago C, Rodriguez-Hernandez A. Adverse events of ERCP at San Jose Hospital of Bogota (Colombia). Rev Esp Enferm Dig. 2009; 101: 837-49.

23. Rabago L, Guerra I, Moran M, Quintanilla E, Collado D, Chico I et al. Is outpatient ERCP suitable, feasible, and safe? Th e experience of a Spanish community hospital. Surg Endosc. 2010; 24: 1701-6.

24. Cotton PB, Garrow DA, Gallagher J, Romagnuolo J. Risk factors for complications aft er ERCP: a multivariate analysis of 11,497 procedures over 12 years. Gastrointest Endosc. 2009; 70: 80-8.

25. Tsou YK, Lin CH, Liu NJ, Tanh JH, Sung KF, Cheng CL et.al. Treating delayed endoscopic sphincterotomy-induced bleeding: epinephrine injection with or without thermotherapy. World J Gastroenterol. 2009; 15: 4823-8. 